\title{
P.W. Contabilidade
}

\section{Editorial}

Inicia-se o oitavo ano da Revista Contemporânea de Contabilidade (RCC). O presente volume oferece 08 (oito) artigos de cunho empírico.

O primeiro artigo, intitulado Análise da Cadeia de Valor: um Estudo no Âmbito da Gestão Estratégica de Custos de Empresas da Construção Civil da grande Porto Alegre, de autoria de Marcos Antonio Souza e Eliane Mello é um estudo de casos múltiplos conduzido junto a três empresas gaúchas de médio porte estabelecidas no Vale do Rio dos Sinos. Partindo da premissa de que a gestão estratégica de custos na cadeia de valor é um instrumento relevante para o estabelecimento e manutenção de diferenciais competitivos em relação à concorrência, o artigo, de natureza exploratória, identifica de que forma os procedimentos de análise da cadeia de valor são adotado por empresas construtoras gauchas.

O segundo artigo, intitulado A Comunicação do Conhecimento Científico: Dados sobre a Celeridade do Processo de Avaliação e de Publicação de Artigos Científicos em Periódicos da Área de Contabilidade, é de autoria de Warley de Oliveira Dias, João Estevão Barbosa Neto e Jacqueline Veneroso Alves da Cunha. O artigo de natureza descritiva, por meio da pesquisa documental em 660 artigos de 08 periódicos vinculados aos programas de pós-graduação stricto sensu em Ciências Contábeis, no período de 2004 a 2009, tem por objetivo identificar e analisar o período de avaliação e publicação dos artigos nesses periódicos.

O terceiro artigo do presente volume, de autoria de Jeniffer Monteiro Rodrigues, Débora Gomes Machado e Ana Paula Capuano da Cruz, intitulado Evidenciação de Custos Ambientais em Empresas do Segmento de Adubos e Fertilizantes, investiga de que forma as empresas brasileiras do segmento de adubos e fertilizantes, que submetem suas ações à BM\&FBOVESPA, têm classificado e evidenciado seus custos de natureza ambiental.

O quarto artigo, Uma Contribuição à Avaliação dos Periódicos Científicos por meio do Balanced Scorecard: Ilustração da Avaliação e Operacionalização da Gestão Estratégica na RCC, é de autoria de Juliane Vieira de Souza, Sergio Murilo Petri e Mariane de Souza Cardoso. O objetivo central da pesquisa é propor a transformação da ação estratégica da RCC em objetivos operacionais, por meio do instrumento Balance Scorecard, de tal forma que a revista seja, até 2015, reconhecida nacional e internacionalmente pela sociedade e órgãos reguladores como veículo disseminador de conhecimentos contábeis.

O quinto artigo, intitulado Análise do Impacto das Mudanças nas Normas Contábeis Brasileiras: um Estudo Comparativo dos Indicadores Econômico-financeiros de Companhias Brasileiras para o ano de 2007, é de autoria de Josué Pires Braga, Marcelo Bicalho Viturino de Araujo, Marcelo Álvaro da Silva Macedo e Luiz João Corrar. O ob- 
jetivo deste estudo, de natureza descritiva, é comparar indicadores econômico-financeiros das 75 empresas brasileiras de capital aberto, listadas na Bovespa, que reapresentaram suas demonstrações contábeis referente ao exercício de 2007, em função da a vigência da Lei 11.638/07 e verificar a ocorrência de mudanças significativas nesses indicadores, como conseqüência deste processo de mudança com vistas a convergência ao padrão internacional.

O sexto artigo do presente volume, de autoria de Janison Machado Albuquerque, intitulado Avaliação dos Controles Internos de uma Instituição Pública de Ensino Superior à Luz da Metodologia MCDA - Construtivista, é um estudo exploratório. Tendo em vista a amplitude dos controles internos no assessoramento dos resultados da gerência operacional das organizações públicas ou privadas e há necessidade de se identificar e avaliar as vulnerabilidades e propor sugestão de aperfeiçoamento na consumação dos controles, este estudo tem por objetivo contribuir com uma Instituição Pública de Ensino Superior ao construir um modelo de avaliação dos controles internos dessa instituição por meio de uma metodologia multicritério, que permita implementar um sistema de controle eficaz por parte dos gestores.

O penúltimo artigo deste volume tem como título O Perfil da Colaboração nos Periódicos Contábeis Nacionais: Muitos One-timers e Poucos Continuants e tem Diego Bevilacqua Meli e José Dutra de Oliveira Neto como autores. O artigo propõe um modelo com três dimensões para analisar e explicar a colaboração científica em Contabilidade no Brasil, em 07 periódicos especializados da área Contábil, no período 2005-2009, sob a óptica da Análise de Redes Sociais.

O trabalho que fecha este volume, de autoria de Gilson Cella, Jomar Miranda Rodrigues e Jorge Katsumi Niyama, Contabilidade Internacional - Análise dos Periódicos Internacionais sobre Pesquisas em Educação Contábil face à Convergência e Globalização, no contexto de convergência e globalização dos relatórios financeiros, analisa 56 artigos com temas relacionados à educação/formação em contabilidade publicados em periódicos técnicos internacionais da área, a fim de verificar quais são as pesquisas em educação contábil.

Esta edição da RCC foi viabilizada com os recursos da Fundação de Estudos e Pesquisas Sócio-Econômicos - FEPESE.

Boas leituras !

Sandra Rolim Ensslin

Editora 